\title{
Chapter 4 \\ Fibre Bragg Grating as a Multi-Stage Structure Health Monitoring Sensor
}

\author{
Gilmar Ferreira Pereira
}

\begin{abstract}
There is a clear need to implement models and measurement systems through the entire life of the wind turbine blade. In this chapter will be presented some work conducted to implement optical fibres as a multi-stage sensor, capable to measure different structural properties, and link them with all the different life stages and support a better design of the wind turbine blades. The characteristics and functionality of fibre Bragg grating sensors are briefly introduced. Their application as multi-stage structure health monitoring sensors for polymer laminate composite is then described. At the manufacturing stage, where the sensors can measure several parameters of infusion and curing, sensor feedback can help control the process, avoid residual strain, and contribute to the product certification; and then in operation where cracks can be detected and monitored. Experimental mechanical testing involving crack growth and fibre Bragg sensing is described that highlights the response from the fibre optic which will correctly detect the presence and growth of damage. Models to implement these results in a damage detection system for a wind turbine blade can then be developed.
\end{abstract}

\subsection{Fibre Bragg Grating Sensors}

Fibre Bragg grating (FBG) sensors are the most commonly used type of sensors in the fibre optic field. An FBG sensor can be embedded in the Fibre reinforced polymer material (main material of the wind turbine blade), without compromising its structural resistance. This is due to the FBG reduced size, with a diameter of $125 \mu \mathrm{m}$ it is virtual non-intrusive to the material. Also, FBG sensors present other interesting features, such high resolution, multiplexing capability, immunity to electro-magnetic fields, chemical inertness and long term stability.

A FBG is formed by a permanent periodic modulation of the refractive index along a section of an optical fibre, by exposing the optical fibre to an interference pattern of intense ultra-violet light. The photosensitivity of the silica exposed to the

\footnotetext{
G.F. Pereira $(\square)$

Department of Wind Energy, Technical University of Denmark (DTU), DTU Ris $\varnothing$ Campus,

Frederiksborgvej 399, 4000 Roskilde, Denmark

e-mail: gilmar.fepe@gmail.com
} 


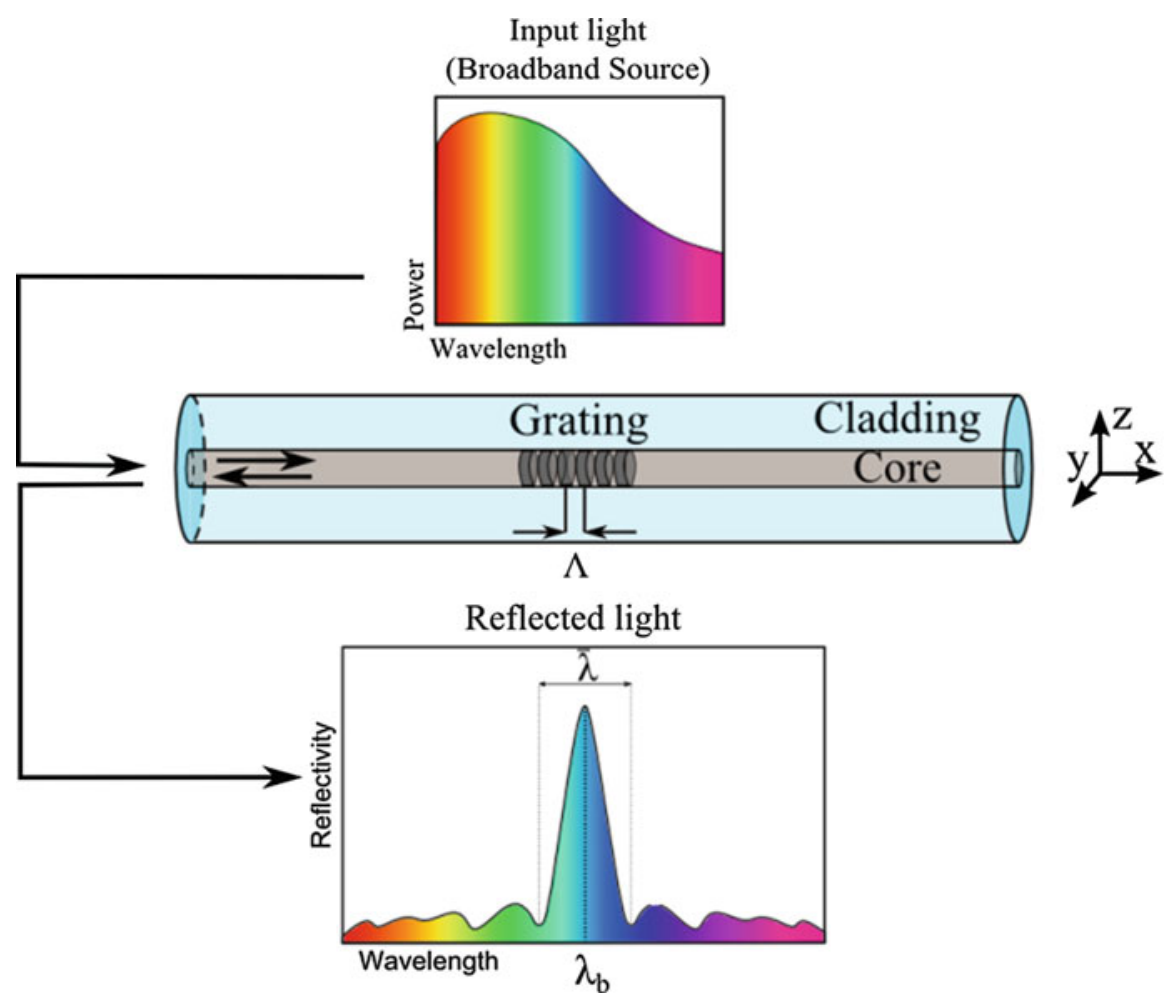

Fig. 4.1 Fibre Bragg grating: strongest mode coupling at the Bragg wavelength

ultra-violet light is increased, so that when light propagates through the periodically alternating regions of higher and lower refractive index within the fibre, it is reflected by successive, coherent scattering from the index variations. When the reflection from a crest in the index modulation is in phase with the next one, it is generated the maximum mode coupling or reflection. The strongest mode coupling occurs at the Bragg wavelength, $\lambda_{b}$, as shown in Fig. 4.1. The wavelength $\lambda_{b}$, is described by the Bragg condition:

$$
\lambda_{\mathrm{b}}=2 \mathrm{n}_{\mathrm{eff}} \Lambda
$$

where $n_{\text {eff }}$ is the mean effective refractive index at the location of the grating and $\Lambda$ is the constant nominal period of the refractive index modulation (Hill and Meltz 1997).

The bandwidth $\bar{\lambda}$ (distance between the two first minima) is given by:

$$
\frac{\bar{\lambda}}{\lambda_{\mathrm{b}}}=\frac{1}{\mathrm{n}_{\mathrm{eff}}} \sqrt{\left(\zeta \overline{\delta \mathrm{n}_{\mathrm{eff}}}\right)^{2}+\left(\frac{\lambda_{\mathrm{b}}}{\mathrm{L}}\right)^{2}}
$$


where $L$ is the gauge length, $\overline{\delta n_{\text {eff }}}$ is the mean induced change in $n_{\text {eff }}$ and $\zeta$ is the amplitude of the induced index change (Peters et al. 2001). An external load or temperature variation will change the effective index of refraction and/or the period of modulation; this will create a shift of the wavelength reflected peak from its original value.

\subsection{Manufacturing Stage: Residual Stress Induced by Resin Shrinkage and Curing Process Control}

The FBG sensors are an excellent choice to monitor the curing process of wind turbine blades, where their capability of surveying the curing process is combined with their capability to monitor strain and other features over the structure lifetime. Because the FBG sensor small size that makes them virtually non-intrusive to the structure, they can be embedded in the composite layers from the first manufacturing step.

This embedded sensor will monitor several parameters of the curing process: temperature of the resin, which enables a retro-feedback of temperature to the process controller; residual stress that are a big issue in the fatigue performance of the composite; resin flow, by measuring the position of dry spots in the laminate; etc. Additionally, the FBG sensor can be used as part of the process certification, by giving information about the curing profile of the structure, the residual stress, the load history during manufacturing, transport and installation.

\subsubsection{Embedded FBG Response to Strain and Temperature Variation}

Assuming a perfect strain transfer between an embedded FBG sensor and the host material, the wavelength shift, $\Delta \lambda_{b}$, under variation of strain in the longitudinal direction of the fibre optic, $\varepsilon_{1}$, and temperature, $\Delta T$, is given by $\operatorname{Eq}(4.3)$ :

$$
\frac{\Delta \lambda_{\mathrm{b}}}{\lambda_{\mathrm{b}}}=\left(1-\mathrm{p}_{\mathrm{e}}\right) \varepsilon_{1}+\left[\left(1-\mathrm{p}_{\mathrm{e}}\right)\left(\alpha_{\mathrm{s}}-\alpha_{\mathrm{f}}\right)+\xi\right] \Delta \mathrm{T}
$$

The parameter $p_{e}$ is the optical fibre photo-elastic coefficients, $\alpha_{s}$ and $\alpha_{f}$ are the thermal expansion coefficient of the host material and the optical fibre, respectively, and $\xi$ is the thermos-optic coefficient (Magne et al. 1997). Figure 4.2 depicts a typical Fibre Bragg grating response. 


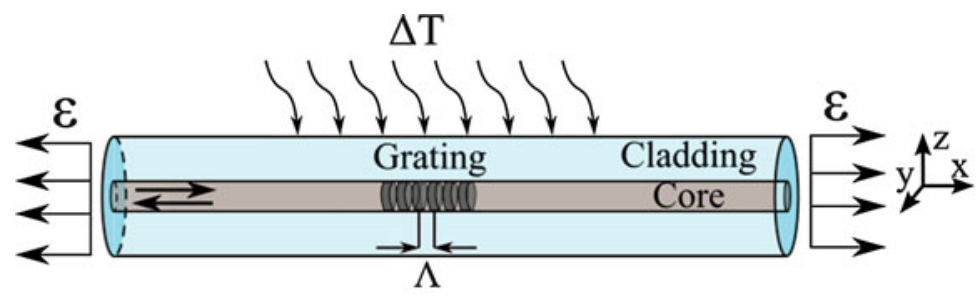

Wavelength Shift: Strain and Temperature

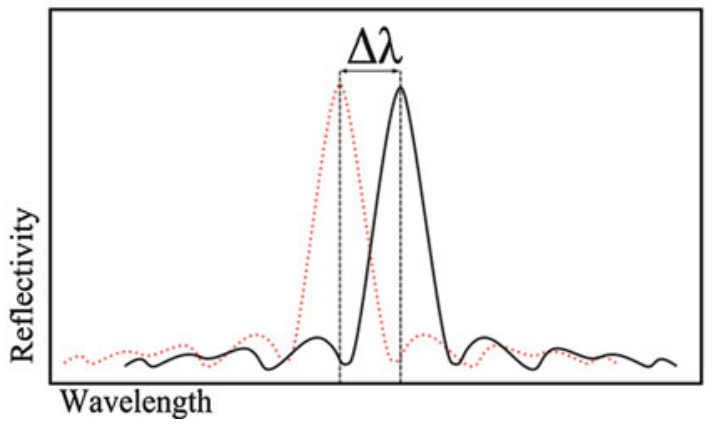

Fig. 4.2 Fibre Bragg grating response: strain and temperature variation

\subsubsection{Residual Stress Measurement}

Curing cycles are often defined on the basis of experience and economical aspects, missing the opportunity to improve curing cycles and blades, by understanding the physic-chemical process. Reducing the reaction time by increasing the temperature leads to a decrease in production time and consequent lower production cost. But this can lead to residual stress induced by the curing process, which causes worst mechanical properties and reduces the fatigue life of the structure. Equation (4.3) was rewritten to measure the residual stress caused by the material shrinkage:

$$
\varepsilon_{\text {shrinkage }}=\frac{\frac{\Delta \lambda_{\mathrm{b}}}{\lambda_{\mathrm{b}}}-\xi \Delta \mathrm{T}}{1-\mathrm{p}_{\mathrm{e}}}+\alpha_{\mathrm{f}} \Delta \mathrm{T}
$$

By measuring the temperature in the resin using a thermocouple, it is possible to decouple the temperature-strain cross sensitivity of the FGB and calculates the epoxy shrinkage. 


\subsection{Operation Stage: Crack Growth Detection by Embedded FBG Sensors}

Often in fibre reinforced polymers (FRP), delamination is accompanied by the formation of a crack bridging zone, where intact fibres connect the crack faces behind the crack tip, as shown in Fig. 4.3. Thus, the energy required for the crack to propagate is higher than required to initiate. The relationships between the crack bridging stresses and the crack opening displacement (bridging laws) are used to describe the effect of fibres on the crack propagation (Sørensen 2010). The cracking in homogeneous isotropic materials usually occurs under pure Mode I (opening loading) but in weak planes or along interfaces, like in composite materials cracking, occurs under a combination of Modes (Shear and opening loading).

In order to detect delamination/crack in FRP materials the sensor/monitoring system need to track specific fracture features that only appear in the vicinities of the

Fig. 4.3 Fibre bridging during delamination of a DCB specimen

\section{Double Cantilever Beam}

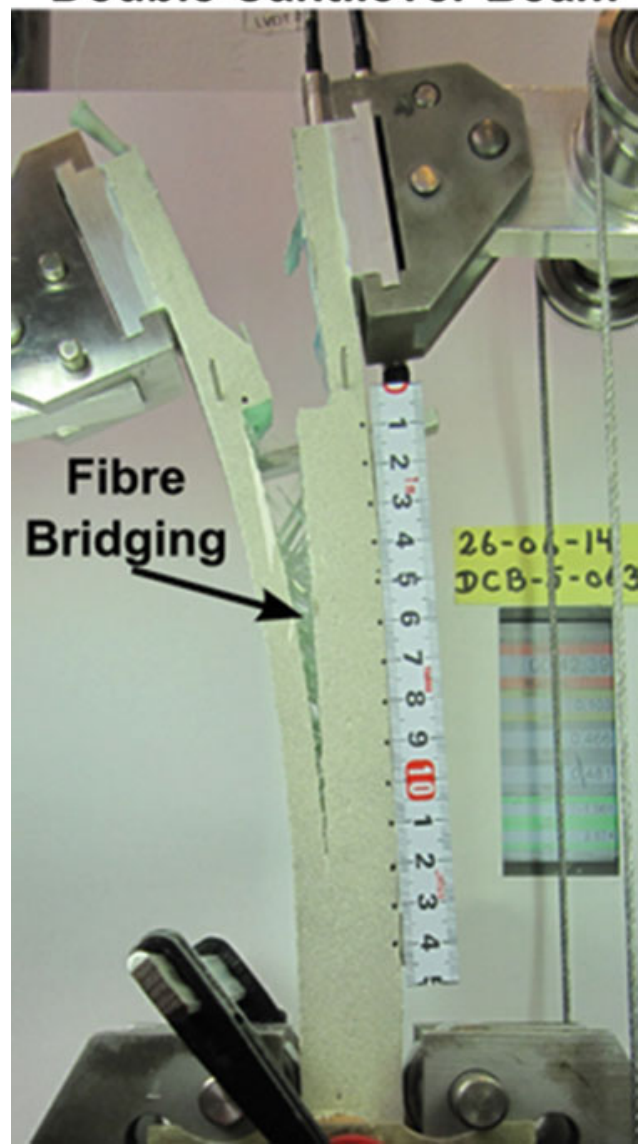



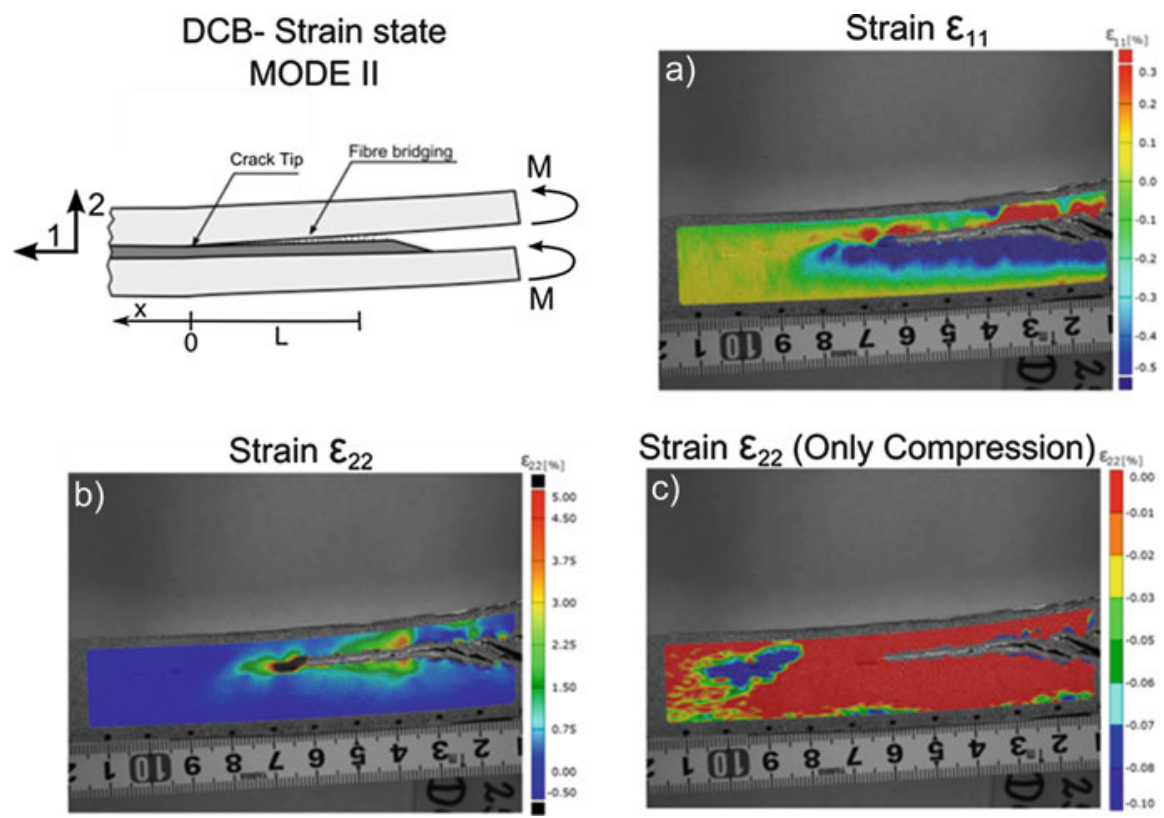

Fig. 4.4 Strain distribution at the crack tip during Mode II fracture (Pereira et al. 2015)

crack, independent of geometry and loading conditions. Thus, to link these fracture features with the measured parameters, the strain distribution around a crack tip during delamination was analysed using Digital Image Correlation (DIC), as shown in Fig. 4.4 (Pereira et al. 2015). The DIC technique is a non-contact optical method that, by tracking changes in a random pattern on the specimen, can correlate it with deformation/strain of the material.

It is possible to divide the strain distribution in two distinct contributions: crack tip singularity/material damage and fibre bridging. Near the crack tip, the stress field closely approaches the singular stress field of linear elastic fracture mechanics. This means that the stress tends to infinity and has a fast variation (high gradient). Also, with the progression of the crack the material/structure losses stiffness increasing the strain, here it is possible to observe higher values of strain $\varepsilon_{11}$ at the crack faces, as showed in Fig. 4.4a. In the fibre bridging zone $(\mathrm{L}<\mathrm{x}<0)$, a positive strain $\varepsilon_{22}$ was observed, due to the forces transferred by the fibre that are connecting the two crack faces, as shown in Fig. 4.4c. These forces are balanced by a compression stress that appears ahead of the crack tip ( $x>0$ ), which creates a negative strain $\varepsilon_{22}$, shown in Fig. $4.4 \mathrm{c}$ as a blue area. 


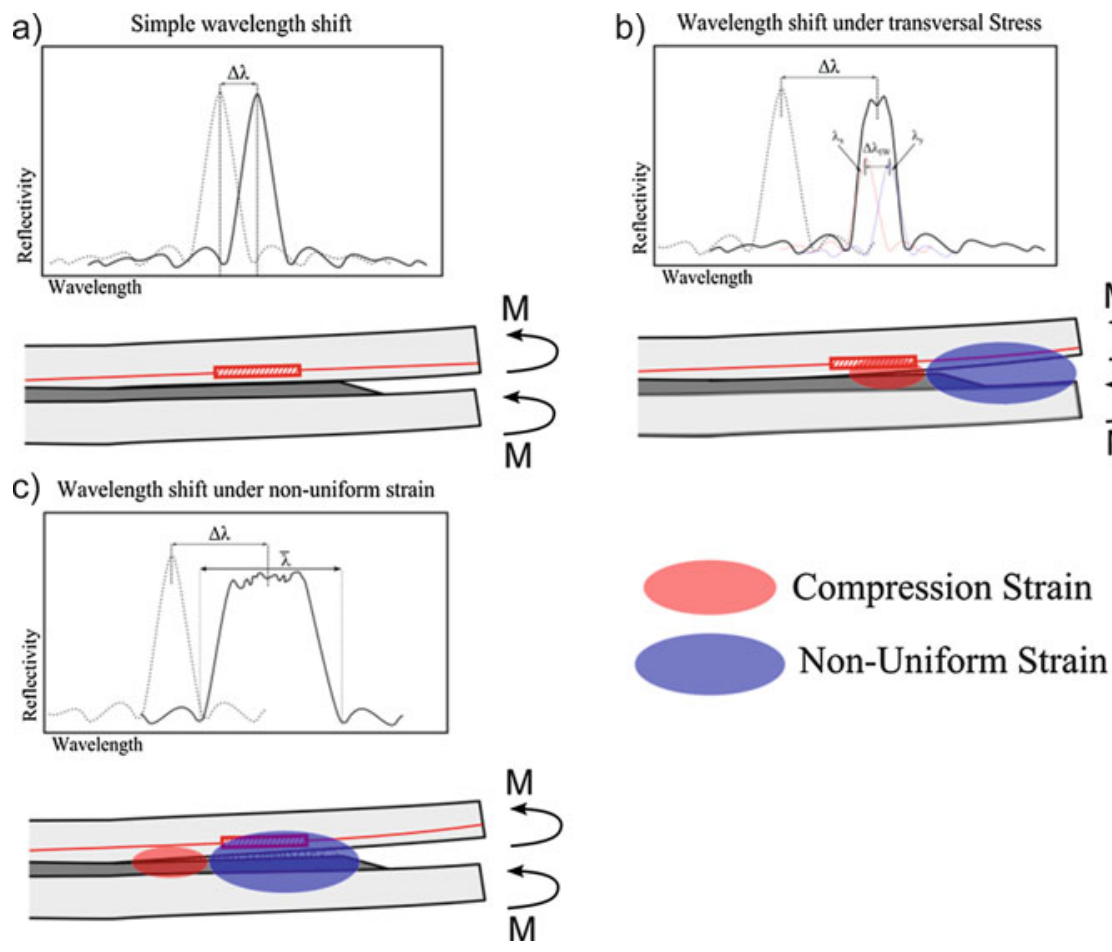

Fig. 4.5 Stages of the FBG response under a crack growth event

\subsubsection{Crack/Delamination Detection by Embedded Fibre Bragg Gratings}

As measured using DIC technique, during a crack/delamination event different fracture features will be present near the crack tip. Being able to identify and measure these specific phenomena with a FBG sensor is the key factor to correctly determine the presence of damage and its growth.

The three different stages of the FBG responses under a crack growth event are presented in Fig. 4.5. First, before the crack reaches the proximity of the grating (Fig. 4.5a), the material will build-up strain, that will create a uniform wavelength shift in the FBG reflected peak. Next, a compression field is formed ahead of the crack tip due to the formation of a crack bridging zone (Fig. 4.5b). When this compression field reaches the grating area it creates a peak splitting of the FGB response. Then, when the grating is near the influence of the crack singularity (Fig. 4.5c), a non-uniform strain field will also modify the shape of the reflected peak. After the crack passes the FBG sensor, the shape of the reflected peak will go back to the original shape, and the sensor response will again be a simple wavelength shift, because at this stage only uniform strains will be present at the FBG. 


\subsubsection{Embedded FBG Response: Strain}

As mentioned before, the FBG response to strain and temperature variation can be described by Eq. (4.3). However, during crack growth the temperature variation can be neglected. The wavelength shift $\Delta \lambda_{b}$ (Fig. 4.5a) is given by (4.5):

$$
\frac{\Delta \lambda_{\mathrm{b}}}{\lambda_{\mathrm{b}}}=\left(1-\mathrm{p}_{\mathrm{e}}\right) \varepsilon_{1}
$$

\subsubsection{Embedded FBG Response: Transverse Stress}

The compression field formed ahead of the crack tip will reach the grating area, which will create a peak split of the FBG reflected signal (Fig. 4.5b). This peak split phenomenon is due to a birefringent effect, which can be defined as the change of the refractive index $n_{\text {eff }}$ in the two directions $n_{\text {effy }}$ and $n_{\text {eff }}$, when the grating is subjected to a transverse force (Sørensen et al. 2007; Jülich and Roths 2010). The increase in the width of the reflected peak, $\Delta \lambda_{w v}$, is given by Eq. (4.6):

$$
\Delta \lambda_{\mathrm{wv}}=2 \Lambda\left|\Delta \mathrm{n}_{\mathrm{effy}}-\Delta \mathrm{n}_{\mathrm{effz}}\right|=\frac{\Lambda \mathrm{n}_{0}^{3}}{\mathrm{E}_{\mathrm{f}}}\left[\left(1-\nu_{\mathrm{f}}\right) \mathrm{p}_{12^{-}}\left(1+v_{\mathrm{f}}\right) \mathrm{p}_{11}\right]\left|\sigma_{\mathrm{y}}-\sigma_{\mathrm{z}}\right|
$$

where $\sigma_{y, z}$ is the transverse stress, $E_{f}$ is the elastic modulus of the optical fibre, $v_{f}$ is the Poisson's ration, $n_{0}$ is the initial refractive index, $p_{11}$ and $p_{12}$ are the photo-elastic coefficients of the optical fibre.

\subsubsection{Embedded FBG Response: Non-Uniform Strain}

A non-uniform strain changes the periodicity of the grating pattern along the sensor length, modifying the grating pattern configuration from "uniform" to "chirped". As demonstrated by Peters et al. (2001), in a uniform grating the applied strain will induce a change in both grating period and the mean index. These two effects can be superimposed by applying an effective strain of " $\left(1-p_{e}\right) \varepsilon_{1}(x)$ ". Then it is possible to rewrite the grating period as:

$$
\Lambda(\mathrm{x})=\Lambda_{0}\left[1+\left(1-\mathrm{p}_{\mathrm{e}}\right) \varepsilon_{\mathrm{x}}(\mathrm{x})\right]
$$

where $\Lambda_{0}$ is the grating period with zero strain. The non-uniform strain effect can be approximated by using the maximum and minimum strain values along the grating. So, the maximum grating period $\Lambda_{\max }$ and minimum $\Lambda_{\min }$ can be calculated using the Eq. (4.1). Thus, an approximated increase of the width of the reflected peak due to a non-uniform strain, $\bar{\lambda}$, is given by combining Eqs. (4.7) and (4.1):

$$
\bar{\lambda}=2 \mathrm{n}_{\mathrm{eff}}\left[\Lambda_{\max }-\Lambda_{\min }\right]
$$




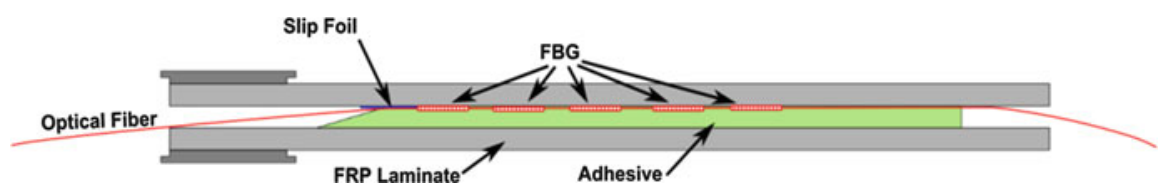

Fig. 4.6 DCB specimen geometry and FBG sensor array configuration

\subsubsection{Delamination Detection in Fibre Reinforced Polymer Specimen Using Embedded FBG Sensor: Material and Testing Procedure}

To validate the crack detection technique double cantilever beam (DCB) specimens were tested in a fracture testing machine, developed by Sørensen (2010). The DCB specimens were loaded with different combination of moments, giving different type of fracture modes that simulates different crack/delamination cases. The DCB specimens were manufactured using two FRP material arms, made of unidirectional and triaxial glass fibre layers (SAERTEX UD and TRIAX), with a layup stacking of : $[90 /+45 /-45 / 04 / 04 /+45 /-45 / 90]$, glued by a commercial epoxy structural adhesive (Epikote MGS BPR 135G/Epikote MGS BPH137G). A thin slip foil was placed in the edge of the structural adhesive, to act as a pre-crack and ease crack initiation.

An array of 5 uncoated single mode (SM) FBG sensors, each with a length of $10 \mathrm{~mm}$, was embedded in the interface of the composite material with the structural adhesive. The gratings array were spaced by $10 \mathrm{~mm}$ from each other, and the first grating was positioned $10 \mathrm{~mm}$ from the edge of the adhesive. In Fig. 4.6, the DCB specimen and FBG sensor array configuration is presented. The sensors were connected to an Optical Spectral Analyser (OSA) FS2200_-Industrial BraggMETER from FiberSensingTM.

\subsubsection{Experimental Results}

In Figs. 4.7 and 4.8, the strain distribution on the surface of the DCB specimen (left pictures) and the FBG sensor output (right picture), before and during the propagation of the crack/delamination are shown. Before the crack starts to propagate in the material, it is observed a build-up of strain caused by the increase of load. Once the crack start to grow, a compression field is formed ahead the crack tip due to the formation of a crack bridging zone. This compression stress area can be observed in Fig. 4.7 (in the top left image, the DIC measurement is shown as a blue spot). At the same time, a decrease in the material compliance due to the growth of the crack causes a rapid local increase of strain, creating a gradient of strain near the crack tip (non-uniform strain), which can be observed in Fig. 4.8 (the bottom left image depicts the DIC measurement). 


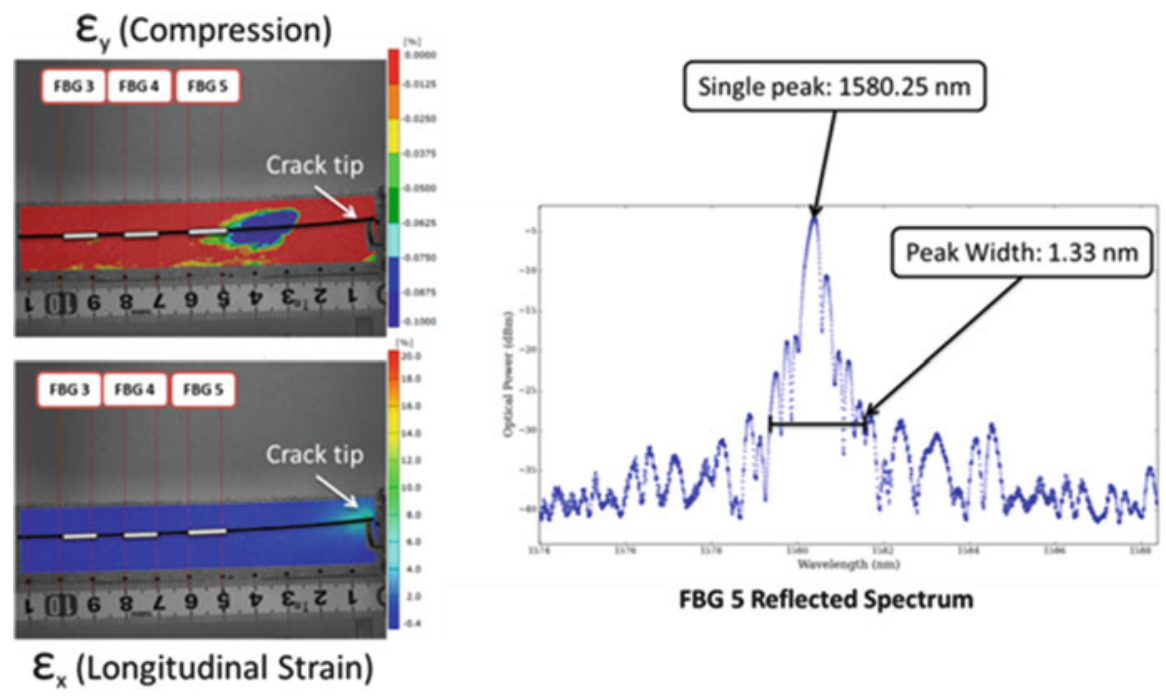

Fig. 4.7 FBG sensor output and DIC measurement before crack growth
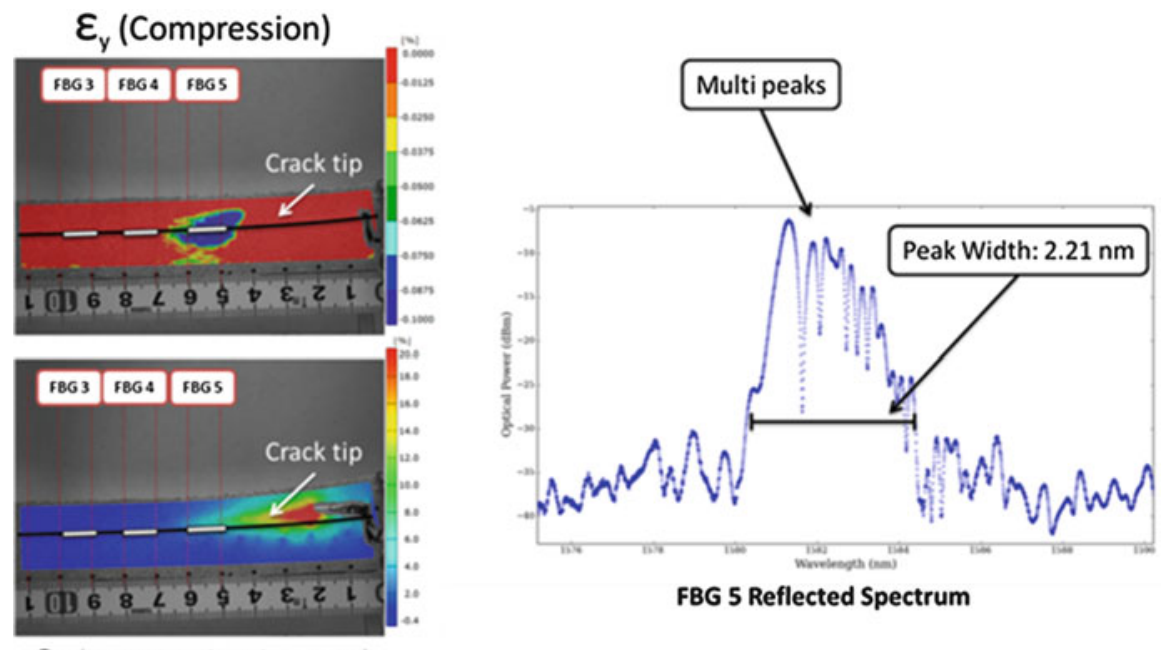

$\varepsilon_{\mathrm{x}}$ (Longitudinal Strain)

Fig. 4.8 FBG sensor output and DIC measurement during crack growth

The wavelength shift and peak width at $-30 \mathrm{dBm}$, computed from the output of the FBG array in three different loading conditions, it is presented in Fig. 4.9. The different colours plotted correspond to each Bragg grating in the sensor array. The FBG5 (Orange colour line) is the grating located closest to adhesive edge and the FBG1 (Black colour line) is the grating more distant. The crack growth in the order: FBG $5 \rightarrow 4 \rightarrow 3 \rightarrow 2 \rightarrow 1$. The wavelength shift is dependent on the loading 


\section{Mode I}

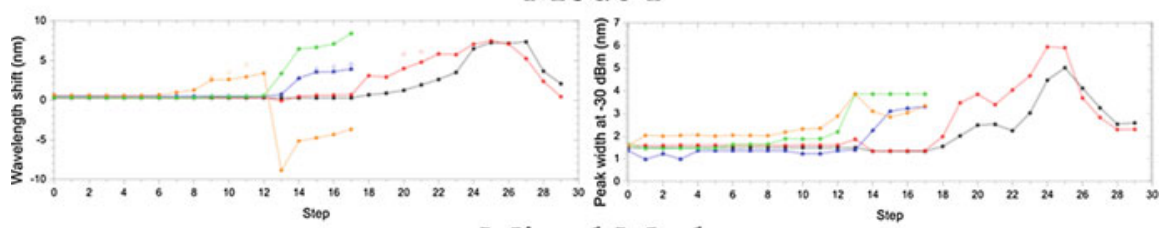

Mixed Mode
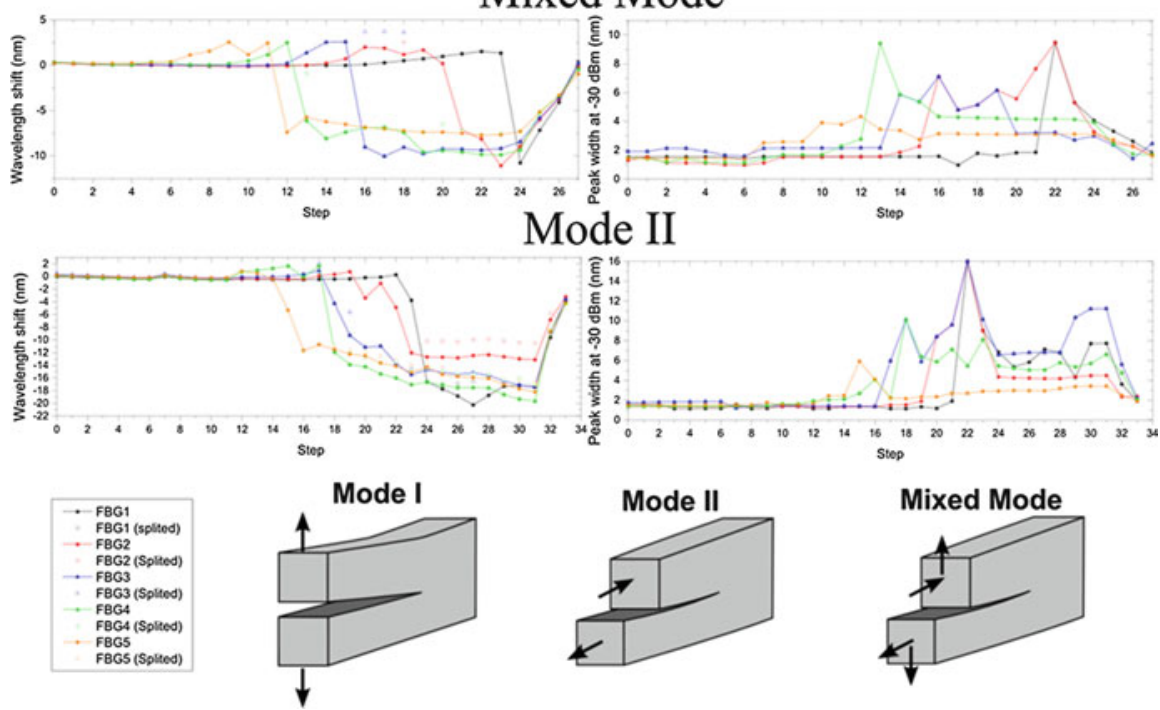

Fig. 4.9 Sensor array output during crack growth

type, but the increase in the width of the peak is related to the presence of the crack (Birefringent effect and non-uniform strain). Using this information it is possible to track the crack by measure an abrupt variation of the wavelength and/or increase in the width of the reflected peak.

\subsection{Application of the FBG Crack Detection Method}

By using this method it becomes possible to extract two types of information from the sensor: one type dependent of the loading and geometry, $\varepsilon_{\mathrm{zz}}$, which give information about the global strain/loading state of the structure; The other type, $\varepsilon_{\mathrm{zz}}(\mathrm{z})$ and $\sigma_{\mathrm{x}, \mathrm{y}}$, independent and only affected by the proximity of a crack.

To demonstrate the applicability of this technique to other structures or materials, this monitoring method was implemented in a Finite Element Method (FEM) Model of the DCB specimen, which simulates the response of the FBG sensor during the process of the crack growth, as shown in Fig. 4.10. 


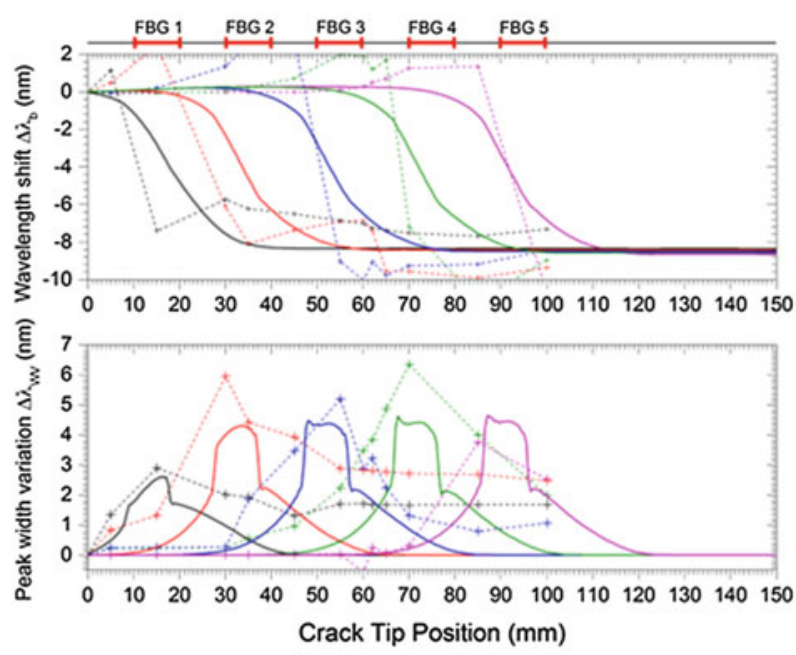

FEM sensor Output: FBG 1

FBG 2

FBG 3

FBG 4

FBG 5

Experimental Data:

FBG 1

FBG 2

FBG 3

FBG 4

FBG 5

\section{FBG Measurement $] \leftrightharpoons$ Model Prediction}

\section{Delamination in DCB Specimen}

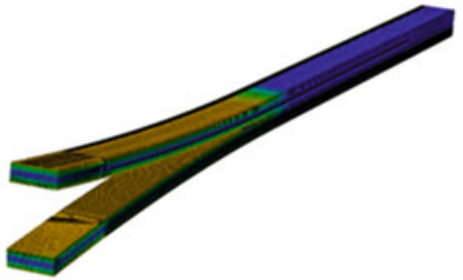

$\sqrt{3}$

Wind Turbine Trailing Edge (Sub-Model)
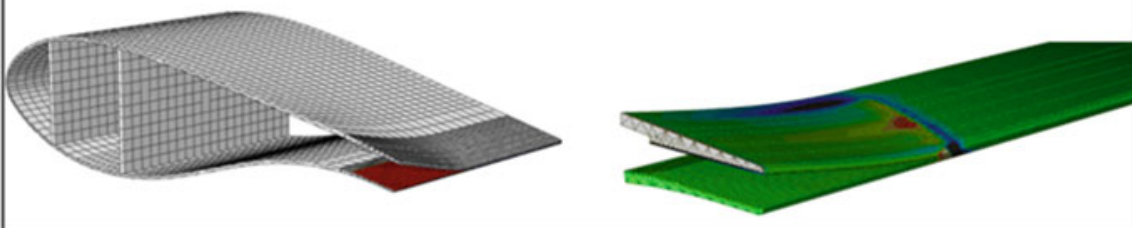

Fig. 4.10 Application of the FBG crack detection method in a DCB specimen and Wind Turbine trailing edge 


\subsection{Fibre Bragg Grating as a Multi-Stage Structure Health Monitoring Sensor: Published Work}

A compiled list of select references pertaining to Fibre Bragg grating sensors and their role in the monitoring structure health at multiple stages:

- Pereira G, Mikkelsen LP, McGugan M (forthcoming) Crack Detection in Fibre Reinforced Plastic Structures Using Embedded Fibre Bragg Grating Sensors: Theory, Model Development and Experimental Validation. Plos One

- Pereira G, Mikkelsen LP, McGugan M (forthcoming) Fibre Bragg Grating Sensor Signal Post-Processing Algorithm: Crack Growth Monitoring in Fibre Reinforced Plastic Structures. Springer Proc Phys

- Pereira G, Mikkelsen LP, McGugan M (2014) Damage tolerant design: failure and crack propagation in composites. In: Abstracts of the 10th EAWE PhD Seminar on Wind Energy in Europe. European Academy of Wind Energy, Orléans, 28-31 Oct 2014

- Pereira G, Mikkelsen LP, McGugan M (2014). FEM model of Embedded Fibre Bragg Grating Sensor Response: Crack Growing Detection. In: Abstracts of the NAFEMS NORDIC - Simulation Verification and Validation (V\&V): A Key Enabler for Virtual Product Development, NAFEMS, Copenhagen, 3-4 November 2014

- Pereira G, Mikkelsen LP, McGugan M (2015) Crack Growth Monitoring by Embedded Optical Fibre Bragg Grating Sensors. In: Abstracts of the 3rd International Conference on Photonics, Optics and Laser Technology, Berlin, 1315 March 2015

- Pereira G, Mikkelsen LP, McGugan M (2015) Embedded Fibre Bragg Grating Sensor Response Model: Crack Growing Detection in Fibre Reinforced Plastic Materials. In: DAMAS 2015. 11th International Conference on Damage Assessment of Structures, Ghent, August 2015. Journal of Physics: Conference Series, Vol 628. Institute of Physics, Temple Back, p 012115. doi:10.1088/1742-6596/628/1/012115

- Pereira G, Mikkelsen LP, McGugan M (2015), Structural Health Monitoring Method for Wind Turbine Trailing Edge: Crack Growth Detection Using Fibre Bragg Grating Sensor Embedded in Composite Materials. Paper presented at the 20th International Conference on Composite Materials, ICCM20, Copenhagen, 19-24 July 2015

Open Access This chapter is distributed under the terms of the Creative Commons AttributionNonCommercial 4.0 International License (http://creativecommons.org/licenses/by-nc/4.0/), which permits any noncommercial use, duplication, adaptation, distribution and reproduction in any medium or format, as long as you give appropriate credit to the original author(s) and the source, provide a link to the Creative Commons license and indicate if changes were made.

The images or other third party material in this chapter are included in the work's Creative Commons license, unless indicated otherwise in the credit line; if such material is not included in the work's Creative Commons license and the respective action is not permitted by statutory 
regulation, users will need to obtain permission from the license holder to duplicate, adapt or reproduce the material.

\section{References}

Hill KO, Meltz G (1997) Fiber Bragg grating technology fundamentals and overview. J Lightwave Technol 15(8):1263-1276

Jülich F, Roths J (2010) Comparison of transverse load sensitivities of fibre Bragg gratings in different types of optical fibres. In: Berghmans F, Mignani AG, van Hoof CA (eds) Optical sensing and detection. SPIE, Brussels, May 2010. SPIE proceedings, vol 7726. SPIE, Washington. doi:10.1117/12.854019

Magne S, Rougeault S, Vilela M et al (1997) State-of-strain evaluation with fiber Bragg grating rosettes: application to discrimination between strain and temperature effects in fiber sensors. Appl Optics 36:9437-9447. doi:10.1364/AO.36.009437

Pereira G, Mikkelsen LP, McGugan M (2015) Embedded fibre Bragg grating sensor response model: crack growing detection in fibre reinforced plastic materials, 2015 In: DAMAS 2015. 11th International conference on damage assessment of structures, Ghent, August 2015. Journal of Physics: Conference Series, Vol 628. Institute of Physics, Temple Back, p 012115. doi:10.1088/1742-6596/628/1/012115

Peters K, Studer M, Botsis J et al (2001) Embedded optical fiber Bragg grating sensor in a nonuniform strain field: measurements and simulations. Exp Mech 41(1):19-28

Sørensen L (2010) Cohesive laws for assessment of materials failure: Theory, experimental methods and application. Dissertation, Technical University of Denmark

Sørensen L, Botsis J, Gmür T et al (2007) Delamination detection and characterisation of bridging tractions using long FBG optical sensors. Compos Part A Appl Sci Manuf 38(10):2087-2096 